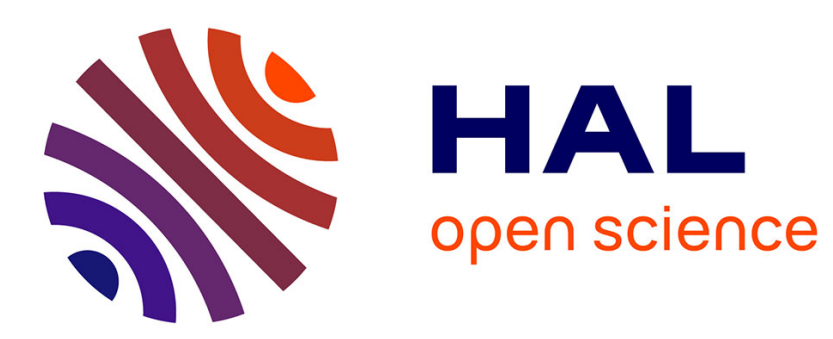

\title{
Aircraft measurements of icing in supercooled and water droplet / ice crystal clouds
}

\author{
M. Bain, Jean-François Gayet
}

\section{To cite this version:}

M. Bain, Jean-François Gayet. Aircraft measurements of icing in supercooled and water droplet / ice crystal clouds. Journal of Applied Meteorology, 1982. hal-01951655

\section{HAL Id: hal-01951655 \\ https://hal.uca.fr/hal-01951655}

Submitted on 8 Jun 2021

HAL is a multi-disciplinary open access archive for the deposit and dissemination of scientific research documents, whether they are published or not. The documents may come from teaching and research institutions in France or abroad, or from public or private research centers.
L'archive ouverte pluridisciplinaire HAL, est destinée au dépôt et à la diffusion de documents scientifiques de niveau recherche, publiés ou non, émanant des établissements d'enseignement et de recherche français ou étrangers, des laboratoires publics ou privés. 


\title{
Aircraft Measurements of Icing in Supercooled and Water Droplet/Ice Crystal Clouds
}

\author{
M. BAIN AND J. F. GAYET \\ L.A.M.P., University of Clermont II, 63170 Aubiere, France
}

(Manuscript received 10 July 1981, in final form 4 December 1981)

\begin{abstract}
Icing measurements were carried out in Spain during the Precipitation Enhancement Project experiment in 1979, with an instrumented DC-7 aircraft.

The energy balance at the riming surface of a cylinder allows the prediction of the ice growth regime (wet or dry) for the present measurements with $85 \%$ success.

The mixed conditions encountered show that the ice phase plays an important role in the ice accretion process. For a range of temperature from -21 to $-8^{\circ} \mathrm{C}$, the icing rate appears to be reduced $\sim 50 \%$ by the presence of large ice particles in concentrations above $5 \mathrm{~L}^{-1}$. The proposed explanation is that the ice particles erode the ice deposit formed by the supercooled water.
\end{abstract}

\section{Introduction}

Icing is a meteorological hazard that may affect any type of airplane and helicopter. Since the use of the latter is becoming increasingly common for both civilian and armed services, the possibility of making them operational in any weather conditions including icing conditions is of prime interest.

Helicopters flying in natural icing conditions have occasionally experienced a sudden rise in the severity of icing (Lake and Bradley, 1976). This effect has been explained by the presence of ice crystals in the supercooled clouds.

Previous experiments have been conducted in an icing wind tunnel in order to study the conditions of icing of a cylinder exposed to mixed icing conditions such as supercooled water droplets and ice particles (Lozowski et al., 1979; Stallabrass and Hearty, 1979). As opposed to prior expectations, icing under mixed conditions does not lead to a greatly enhanced icing rate, within the limited range of the conditions investigated. In some cases, a small reduction in the mass growth rate is even observed. However, the ice phase of the mixed clouds artificially produced by using nozzles or by injection of recently fallen snow into the tunnel leads, in the first case, to an unknown mixture of liquid water and ice; and in the second case, to an inadequate simulation in the structure of natural ice particles due to the breakup of the injected snow crystals.

In order to study natural icing conditions, in situ measurements were carried out with an instrumented
DC-7 aircraft. ${ }^{1}$ The instrumentation and mounting location were as follows (Gayet and Friedlander, 1979):

- Three probes from Particle Measuring Systems (PMS) which give particle spectra with diameter ranges (FSSP) 3-45 $\mu \mathrm{m},(1 \mathrm{D}-\mathrm{C}$ ) $20-300 \mu \mathrm{m}$ (1DP) $300-4500 \mu \mathrm{m}$.

- A Johnson-Williams liquid water content probe.

- A total water content probe similar to the one described by Ruskin (1966); These probes were mounted on the radome on top of the fuselage, just back of the wings.

- An icing probe located on the airplane flank in front of the wing.

- A $3 \mathrm{~cm}$ PPI radar positioned under the fuselage.

This instrumentation was complemented by the usual thermodynamic devices, namely, the Rosemount probe, a Cambridge probe and a pitot tube. A Doppler radar and two inertial platforms provided the dynamical and navigational parameters. The spatial resolution of electronically recorded data was $\sim 100 \mathrm{~m}$ for all the parameters $\left(V \approx 100 \mathrm{~m} \mathrm{~s}^{-1}\right)$.

The experiment was carried out from Valladolid airport in an area in the northwest of Spain during the preliminary phase (SSP3) of the Precipitation Enhancement Project (PEP) of the World Meteo-

'The AMOR DC-7 aircraft is sponsored and operated by the Direction des Recherches Études et Techniques and by the Centre d'Essais en Vol de Brétigny. 
rological Organization (WMO) from 27 March to 4 April 1979. The experimental area is displayed in Fig. 1.

This paper describes some results of icing rate measurements connected with meteorological parameters during penetrations into stratiform and cumuliform clouds.

\section{Procedures}

\section{a. Icing measurements}

The non-rotating icing cylinder consists of a rod made of aluminum alloy $500 \mathrm{~mm}$ long with a diameter of $25.4 \mathrm{~mm}$. Its free end is covered by a disk of $85.0 \mathrm{~mm}$ diameter as shown on Fig. 2, which is useful in visualizing the cross section of the deposit.

The location of the icing probe suggests that the end of the cylinder (at $500 \mathrm{~mm}$ from the fuselage) is outside the airplane boundary layer which has a thickness estimated to be less than $200 \mathrm{~mm}$ by the aircraft engineers. A study relative to a C $130 \mathrm{E}$ aircraft (Norment, 1976) showed that a very light perturbation in concentration $(<20 \%)$ is found for cloud droplets with diameter $<50 \mu \mathrm{m}$ at a location similar to the one of the icing probe. Therefore, no effect of the airplane flow field on droplet concentrations has been taken into account.

The icing probe is filmed sideways, with a $16 \mathrm{~mm}$ movie camera, in order to provide an overall picture of the nature of the icing, its shape and the type of ice. The framing rate of the camera is about one frame every $13 \mathrm{~s}$.
The icing rate $R$ is deduced from the measurements of the increase of the ice deposit cross section $\Delta S$ near the end disk: $R=\Delta S / \Delta t$. The sampling time interval $\Delta t$ is chosen from $40 \mathrm{~s}$ ( 3 frames) to $350 \mathrm{~s}$ (27 frames) in order to obtain a noticeable growth of the ice deposit, leading to a relative error of less than $20 \%$ of the icing rate, estimated from calculation of the error on the measurements of the cross section area of the ice deposit.

\section{b. Meteorological parameters}

\section{1) TEMPERATURE $T_{a}$}

The air temperature is obtained from the total temperature given by the Rosemount probe after the adiabatic correction from the total pressure to the static pressure is applied. These two latter parameters were provided by a Pitot tube and a static pressure probe respectively. A simple estimate shows that the absolute error in the air temperature is $\sim 0.5^{\circ} \mathrm{C}$. The information on air temperature is reliable only for flights in dry air or in cloud with a small liquid water content (Guillemet and Isaka, 1979).

\section{2) Concentration of large ice particles $C_{i}$}

On the DC-7 no direct measurements of ice particle concentration were available. However some estimates can be made by comparison of the present measurements made with the $1 D-C$ and $1 D-P$ probes to the microphysical measurements performed by the University of Wyoming team with their instrumented

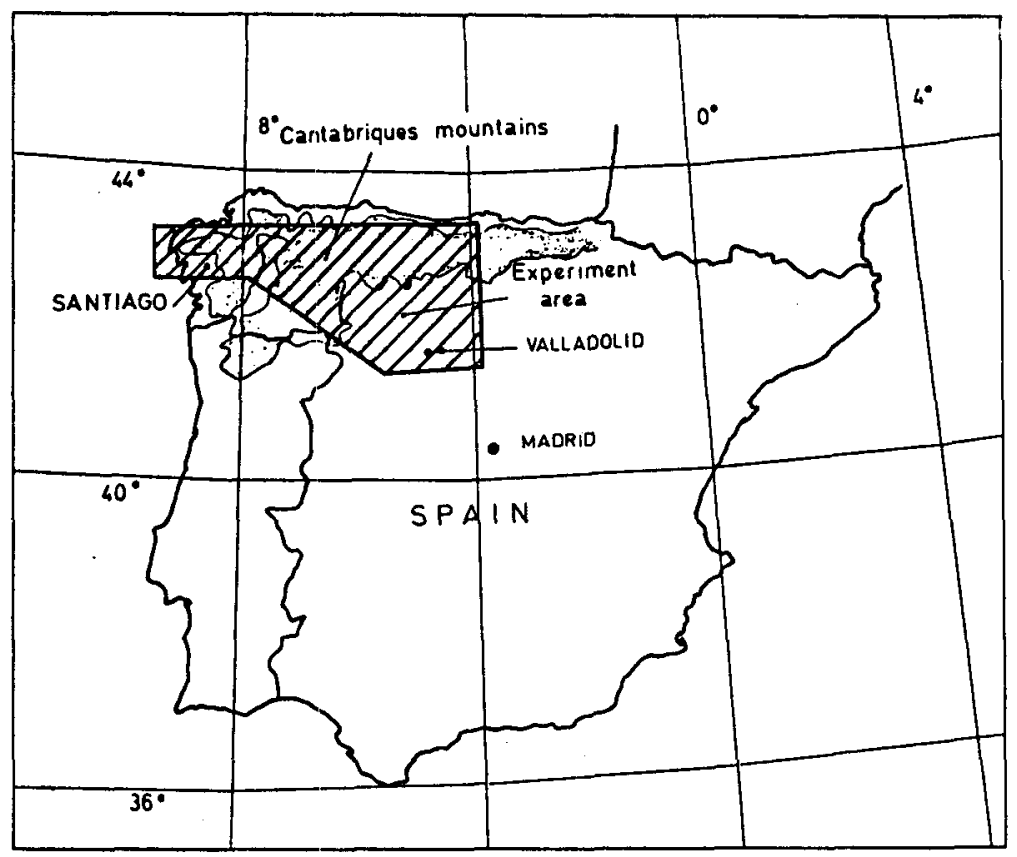

FIG. 1. Experimental area during the PEP experiment 1979. 


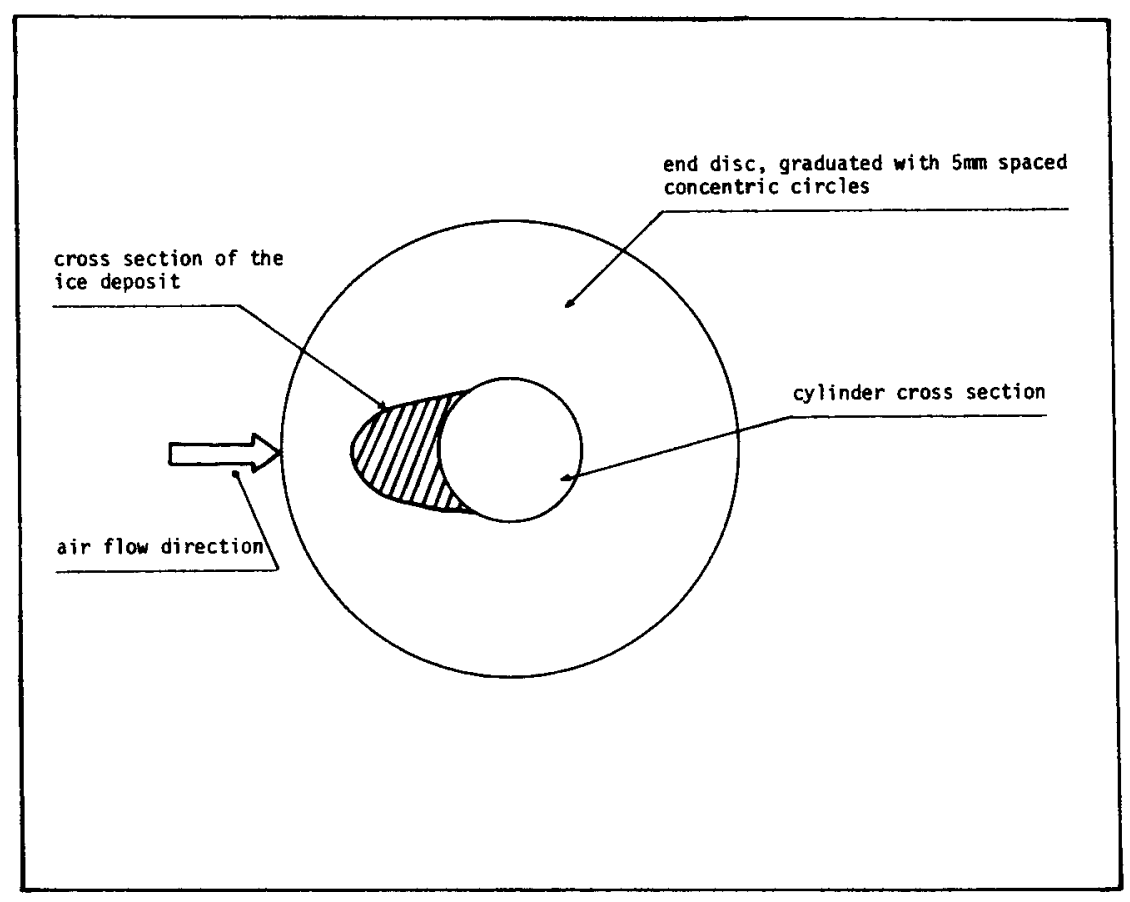

FIG. 2. Drawing of the cross section of the icing probe.

Queen Air aircraft during the same period of the PEP experiment.

Using an impactor device and a 2D-C probe, Vali (1980) shows that, in all the studied clouds and during the whole period, no raindrop with a diameter $>200 \mu \mathrm{m}$ was present in the supercooled part of the clouds, implying that all such particles were ice particles. Assuming that the orientation of the ice particles was random, the concentration of particles with an apparent diameter $>200 \mu \mathrm{m}$ (as measured by the 1D-C and 1D-P probes) can be considered to be of the same order of magnitude as the concentration of ice particles of comparable size. Despite the fact that the true ice concentration cannot be measured accurately due to the probe limitations, the $1 \mathrm{D}-\mathrm{C}$ and 1D-P measurements defined above can be used to relate the values of the icing rate presented in this paper to the different cloud microstructures.

\section{3) LIQUid WATER CONTENT $W$}

The liquid water content (LWC) is available from the Johnson-Williams probe and from integration of the FSSP spectra. In fact, the JW probe is considered more reliable than the FSSP, due to errors created by the electronic circuitry of the FSSP in case of droplet coincidence in the laser beam. According to Heymsfield and Parrish (1979), these errors should not influence the size spectra or the median volume diameter, but they will decrease the concentration. The accuracy of the JW is $\sim 20 \%$ and recent results show that this probe underestimates the liquid water content for droplets of diameter $>30 \mu \mathrm{m}$ (Personne et al., 1980).

\section{4) Cloud droplet concentration $C$}

The cloud droplet concentration is given by the FSSP probe (without any correction) corresponding to droplets with radius between 3 and $45 \mu \mathrm{m}$.

\section{5) Median volume diameter $d_{0}$}

The median volume diameter is such that half of the liquid water is contained in particles of diameter smaller than $d_{0}$, and the other half is in particles of larger diameter. This parameter is estimated from the FSSP spectrum.

To illustrate these definitions, Fig. 3 displays an example of the time variation of the icing rate correlated with the microphysical parameters. This example is relative to a flight performed in the northern part of the experimental area, over the Cantabrique mountains. The flow in the low layer was from north to south indicating a maritime origin of the air mass. The sampled clouds were cumulus congestus. The flight level was near the cloud top where the temperature was between -21 and $-19^{\circ} \mathrm{C}$ and the pressure $\sim 621 \mathrm{hPa}$. The fluctuations in the concentration of large ice particles, in the liquid water content and in the droplet concentration are large, while the 


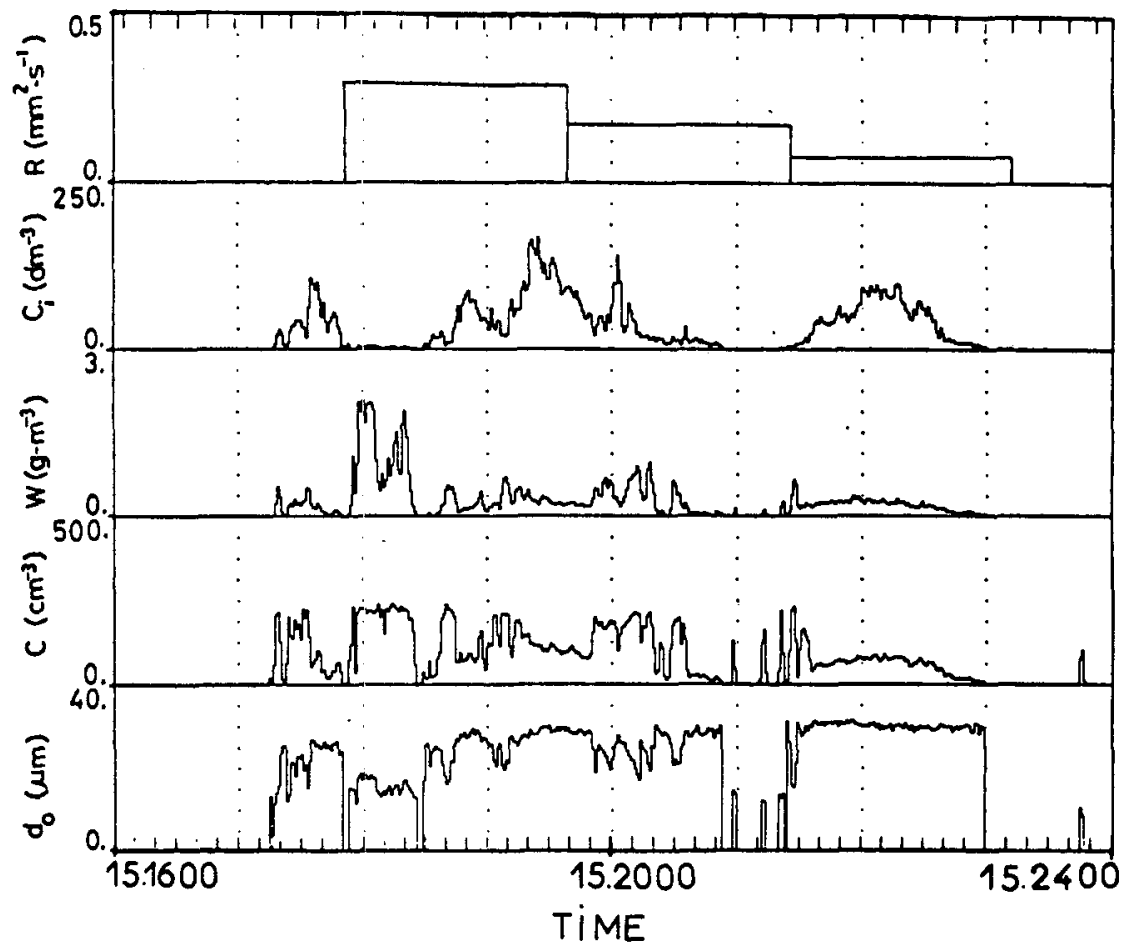

FIG. 3. Time variation of the median volume diameter $d_{0}$, the cloud droplet concentration $C$ given by the FSSP, the liquid water content $W$, the concentration of large ice particles $C_{i}$ and the icing rate $R$. The cloud penetration lasted six min which corresponds to $36 \mathrm{~km}$ of distance. The clouds sampled were maritime cumulus congestus. The flight level was near the cloud top where the temperature was between -21 and $-19^{\circ} \mathrm{C}$, and the pressure $\sim 621 \mathrm{hPa}$.

median volume diameter has a more constant value during the presented period.

We note here that some justification is required for (i) the use of the JW probe for liquid water content (which only takes into account droplets with diameter $<30 \mu \mathrm{m}$ ), rather than the LWC calculated for droplets with diameter from 3 to $200 \mu \mathrm{m}$ (this latter value being the assumed limit value between droplets and ice particles); and (ii) the use of the median volume diameter limited to the range 3-45 $\mu \mathrm{m}$, rather than from 3 to $200 \mu \mathrm{m}$.

For the penetrations of stratiform clouds, the maximum value of the liquid water content calculated by integration over the spectra of the 1D-C probe, and limited to the diameter range $50-200 \mu \mathrm{m}$, is $\sim 0.01 \mathrm{~g} \mathrm{~m}^{-3}$, assuming that all the particles are cloud droplets. This value is $10-90$ tirnes smaller than the liquid water content measured by the JW probe which receives droplets of $d<30 \mu \mathrm{m}$. Under these conditions, the median volume diameter calculated over the spectra from 3 to $200 \mu \mathrm{m}$ is $15 \mu \mathrm{m}$ and is not very different from the median volume diameter calculated over the spectra of the FSSP (3-45 $\mu \mathrm{m}$ ), which is $13.7 \mu \mathrm{m}$.

For the cumuliform cloud penetrations, the maximum value of the liquid water content calculated for the spectra $50-200 \mu \mathrm{m}$ is $0.39 \mathrm{~g} \mathrm{~m}^{-3}$ assuming that all the particles of these sizes are cloud droplets. This value is large and the global median volume diameter $(3-200 \mu \mathrm{m})$ is then $50.3 \mu \mathrm{m}$, while the median volume diameter $(3-45 \mu \mathrm{m})$ is $28.7 \mu \mathrm{m}$. However, the assumption that all particles between 50 and $200 \mu \mathrm{m}$ are cloud droplets is not realistic and, in fact, both cloud droplets and ice particles are probably present. Unfortunately, the measurements do not allow one to state precisely the proportion of the two types. The temperatures at flight level ranged from -21 to $-8^{\circ} \mathrm{C}$ in the cumuliform clouds and most were near $-20^{\circ} \mathrm{C}$. Under such conditions, there is not likely to be much water in the form of large drops. Moreover, the variation of the concentration of large ice particles with median volume diameter presented in Table 1 indicates that ice multiplication processes are active in the sampled clouds. It is therefore reasonable to assume that the larger particles in the range $50-200 \mu \mathrm{m}$ are ice particles, that the part of the liquid water content in droplets of diameter greater than $50 \mu \mathrm{m}$ is small, and that the water content contributed by ice particles of diameter greater than $50 \mu \mathrm{m}$ is also small due to the small value of the ratio of the weight to the apparent volume of the ice particles. Therefore, for the present 
TABLE 1. Meteorological parameters. From left to right: $\Delta t$ the sampling time internal; $T_{a}$ the air temperature; $P$ the pressure; $V$ the air velocity; $d_{0}$ the median volume diameter; $C$ the cloud droplet concentration; $W$ the liquid water content; $C_{i}$ the concentration of large ice particles; $R$ the icing rate; $S$ the observed growth regime for dry growth (open triangles) and for wet growth (circles); $W_{0}$ the calculated critical liquid water content.

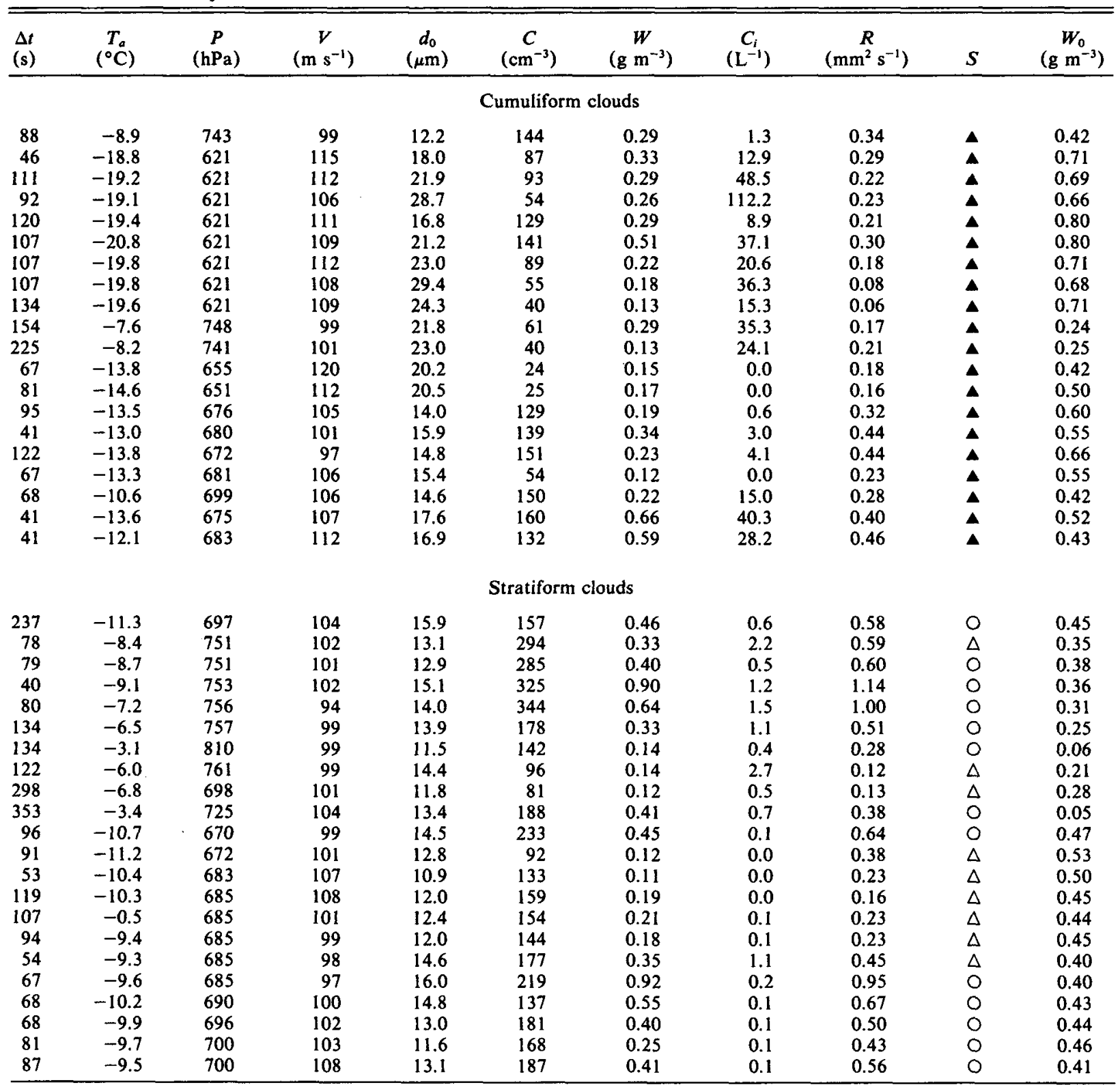

study, the cloud droplet spectrum is limited to the range 3-45 $\mu \mathrm{m}$ for both stratiform and cumuliform clouds.

The parameter $C_{i}$, the concentration of large ice particles, underestimates the true ice concentration, but that does not influence the qualitative result presented in this paper. In Section 3 the results of the calculations will be discussed on the basis of these assumptions.

\section{Icing characteristics}

\section{a. Morphological aspect}

\section{1) Calculation of the critical lwC}

The ice morphology is mainly governed by the ice surface temperature which depends upon the heat budget at the riming surface (Ludlam, 1951).

With the assumption that heat conduction into the 
interior of the ice deposit is small, the equilibrium equation is (Lozowski et al., 1979)

$$
q_{f}+q_{v}+q_{k}+q_{c}+q_{e}+q_{w}=0
$$

where by using the symbols defined in the appendix, we have

$$
\begin{aligned}
& q_{f}=R_{w} l_{f} \\
& q_{v}=\mathrm{h}\left(\boldsymbol{r} V^{2} / 2 C_{p}\right)
\end{aligned}
$$

the latent heat of freezing due to the impinging water droplets

the kinetic heat gain due to the air stream, where $r$ is the recovery factor, $h$ the convective heat transfer coefficient
$q_{k}=R_{w}\left(V^{2} / 2\right)$

$q_{c}=h\left(T_{a}-T_{s}\right)$

$q_{e}=h\left(P_{r} / S_{c}\right)^{0.63}$

$\times\left(\epsilon l_{v} / P C_{p}\right)$

$\times\left[l_{s}\left(T_{a}\right)-l_{s}\left(T_{s}\right)\right]$

$q_{w}=R_{w} C_{w}\left(T_{a}-T_{s}\right)$

the kinetic energy of impinging water droplets

the convective heat loss the evaporative heat loss

the sensible heat loss due to the warming of the impinging water from $T_{a}$ to $T_{s}$.

In the case of ice particles, when other terms of smaller magnitude must be added to the balance equation. $R_{w}$ is the rate at which water mass is caught per unit area on the front half of the cylinder, and is a function of the liquid water content $W$ through the relation

$$
R_{w}=(2 / \pi) E\left(d, D, P, T_{a}, V\right) V W \quad\left[\mathrm{~kg} \mathrm{~m}^{2} \mathrm{~s}^{-1}\right] .
$$

Here $V$ is the air velocity and $E$ the collection efficiency of the droplets of diameter $d$ impinging on the cylinder of diameter $D$, at a temperature $T_{a}$ and pressure $P$.

For the purpose of critical LWC calculation, it is assumed that the stagnation line value of the heat transfer coefficient

$$
h=k_{a}\left(\frac{\rho_{a} V}{\mu_{a} D}\right)^{1 / 2}
$$

is representative of the whole cylinder.

The collection efficiency was estimated from the formulation presented by Lozowski et al. (1979), by using the median volume diameter $d_{0}$ rather than the complete droplet distribution function. This parameter is most representative of the liquid water content of the droplet distribution, which is a significant parameter for the icing study. This simplification does not significantly affect the result of the calculation (Ackley and Templeton, 1979). A more complete discussion of the value of the collection efficiency will be given in the next section.

Under these assumptions, the critical liquid water content below which the droplet can be completely frozen (dry growth) is determined by the following relation, obtained by setting the surface temperature $T_{s}$ equal to $T_{0}=0^{\circ} \mathrm{C}$ :

$$
W_{0}=-h \frac{\left(T_{a}-T_{0}\right)+\left(P_{r} / S_{c}\right)^{0.63}\left(\epsilon l_{v} / P C_{p}\right)\left[l_{s}\left(T_{a}\right)-l_{s}\left(T_{0}\right)\right]+r V^{2} / 2 C_{p}}{E V(2 / \pi)\left[C_{w}\left(T_{a}-T_{0}\right)+l_{f}+V^{2} / 2\right]}
$$

A plot of the critical liquid water content versus air temperature is shown in Fig. 4 for various values of the median volume diameter, covering the range of conditions met in the present experiment (i.e., from 10 to $30 \mu \mathrm{m}$, with $V=100 \mathrm{~m} \mathrm{~s}^{-1}, D=25.4$ $\mathrm{mm})$. The values of the constants used for the calculation are given in the appendix.

When the liquid water content is greater than the critical liquid water content, the ice grows wet and run-back and run-off of water may occur. In this condition, the resulting ice is glassy and hard (socalled glaze ice). On the other hand, when the liquid water content is lower than the critical liquid water content, the ice grows dry; the supercooled droplets may completely freeze during the impact leading to a white and more fragile ice (so-called rimed ice).

These two types of ice growth have been observed during the experiment, the first characterized by a horned shape of the deposited ice and the second one by an elliptical shape. This characteristic has been used to discriminate between the two types of ice growth since the color and aspect of the ice were not apparent on the frames.

\section{2) EXPERIMENTAL RESULTS}

The values of the parameters in Table 1 are mean values calculated over the sampling time interval of the icing rate measurements, indicated in the first column. As the icing rate is proportional to the LWC and as the median volume diameter $d_{0}$ is almost constant during any penetration, this procedure does not lead to large errors. The cumuliform and stratiform cloud penetrations were made over temperature ranges of -21 to $-8^{\circ} \mathrm{C}$ and -11 to $-3^{\circ} \mathrm{C}$; the liquid water content ranged from 0.12 to $0.66 \mathrm{~g} \mathrm{~m}^{-3}$ and from 0.11 to $0.92 \mathrm{~g} \mathrm{~m}^{-3}$, respectively. Fig. 5 shows the measured values of the liquid water content versus the critical liquid water content. The area above the $45^{\circ}$ line corresponds to wet growth; the area below to dry growth. A good agreement appears be- 
tween the observed and the predicted types of icing regime for 36 measurements out of $42(\sim 85 \%)$. Three of the six exceptions are very close to the theoretical limit and they can be attributed for the most part to the difficulty of evaluating the shape of the ice deposit, to the poor accuracy of the liquid water measurement, and perhaps also to the various assumptions made during the evaluation of the critical liquid water content. The discrepancy for the three other penetrations is more noticeable and it should be noted that all these observations occurred immediately after long periods of growth of the opposite kind. Since the change of shape associated with the change of growth regime is not immediately observable, this explains our difficulty in correctly identifying the new growth regime.

\section{b. Quantitative comparison}

\section{1) EXPRESSION OF THE ICING RATE}

The dependence of the icing rate upon the parameters presented in Table 1 can be expressed by using

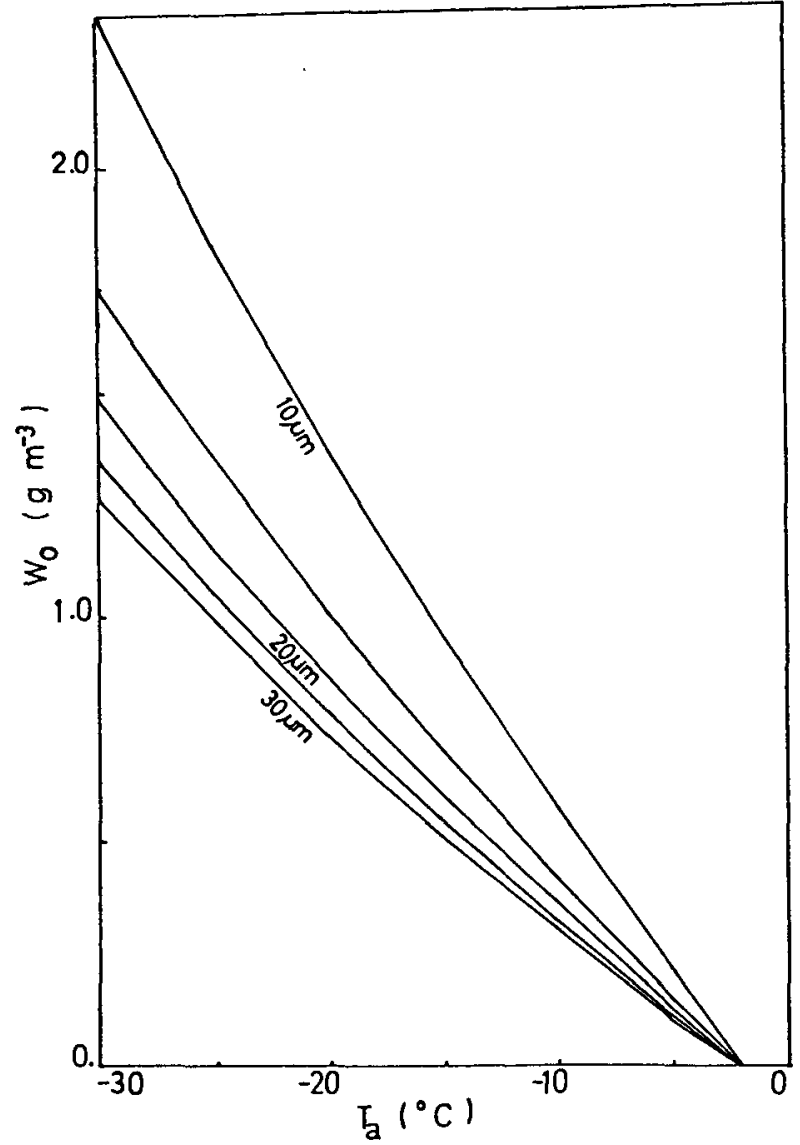

Fig. 4. Critical liquid water content as a function of the air temperature for various droplet diameters. This plot is established for an air velocity $V=100 \mathrm{~m} \mathrm{~s}^{-1}$, pressure $P=730 \mathrm{hPa}$, and for a cylinder of $D=25.4 \mathrm{~mm}$ diameter.

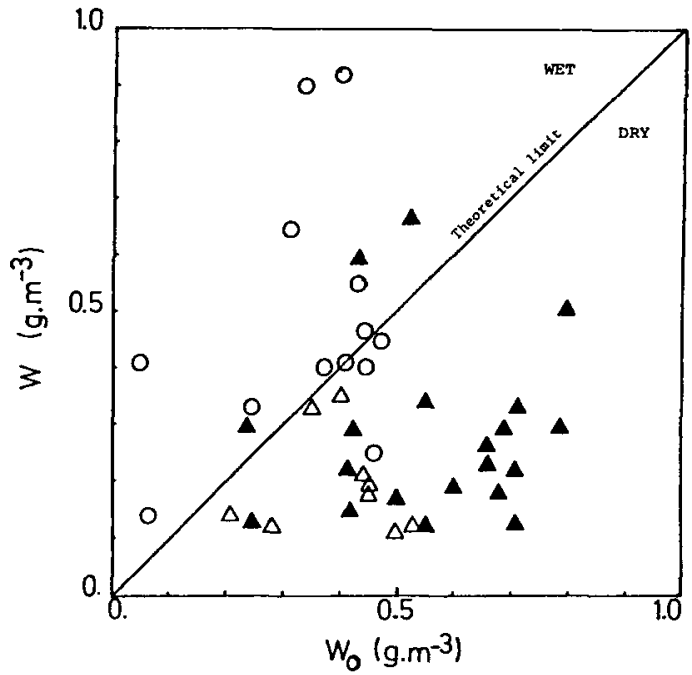

FIG. 5. The measured liquid water content versus the calculated critical liquid water content. Solid or open triangles correspond to an observed dry growth, open circles correspond to an observed wet growth. Dark symbols are relative to cumuliform clouds and white symbols to stratiform clouds. The bisector separates the wet growth regime (above) from the dry growth regime (below).

a relation between the mass of the ice $\Delta m$ accreted on a cylinder of diameter $D$ (assuming complete freezing of all impinging drops) during a time interval $\Delta t$ :

$$
\Delta m=E\left(D, d_{0}, T_{a}, P, V\right) V W D l \Delta t,
$$

where $E\left(D, d_{0}, T_{a}, P, V\right)$ is the global collection efficiency of the rod. The accreted ice mass may also be expressed as

$$
\Delta m=(\Delta S)_{l} l \rho,
$$

where $(\Delta S)_{t}$ is the theoretical increase of the cross section of the ice deposit during the same time interval.

The calculated icing rate $R_{c}$ can be expressed as

$$
R_{c}=(\Delta S)_{\imath} / \Delta t=E V D W \rho^{-1},
$$

where $E$ is evaluated by using the formulation of Lozowski et al. (1979). In fact, the flow field and the apparent diameter of the fixed cylinder change with the increasing cross section of the profile $S$, implying a change in the collection efficiency. Therefore, in order to express the mean icing rate corresponding to a long time interval $\Delta t$, an integration over the apparent cylinder diameter would be required; such a calculation, however, is not practical because of the complexity of the relationship between $E, D$ and the flow field. According to Ackley and Templeton (1979), the collection efficiency decreases with the increase of the ice deposit for the case of the growth regime corresponding to an elliptical profile. On the other hand, the increased surface roughness tends to 
enhance the collection efficiency, but as shown by Stallabrass (1978), this effect cannot be easily quantified.

During the present experiment, no measurements of the density of ice were made. Therefore, this quantity nust be estimated by using the wind tunnel measurements made by Macklin (1962) for air velocities $<15 \mathrm{~m} \mathrm{~s}^{-1}$. Macklin has shown that, for his experimental conditions, the density of ice is a function of the ratio $\left(r_{0} V_{0} / T_{s}\right)$ (his Fig. 8), where $r_{0}$ is the median volume droplet radius and $T_{s}^{\prime}$ the surface temperature. The impact velocity $V_{0}$ of the droplets depends on the size of the droplet and on the cylinder diameter. The values of $V_{0}$ are computed using the method suggested by Langmuir and Blodgett (1946) and for the present experimental conditions range from 43 to $78 \mathrm{~m} \mathrm{~s}^{-1}$ (airplane velocity of $100 \mathrm{~m} \mathrm{~s}^{-1}$ ). The surface temperature $T_{s}$ may be determined using the equation of the energy balance at the riming surface [Eq. (1)]. For negative surface temperature, the ratio $\left(r_{0} V_{0} / T_{s}\right)$ may reach values greater than 50. Since Macklin's results indicate that for this condition the ice density takes the limiting value $\rho$ $=914 \mathrm{~kg} \mathrm{~m}^{-3}$, it is reasonable to adopt it for the measurements in both the dry and wet growth regimes. Since the air velocity is high, the real density of the ice deposit should be close to this assumed value.

\section{2) Comparison BetWeEn the MEASUREd ICING RATE AND THE CALCULATED ICING RATE}

Figs. $6 \mathrm{a}$ and $6 \mathrm{~b}$ represent the measured icing rate $R$ versus the icing rate $R_{c}$ calculated from Eq. (5)

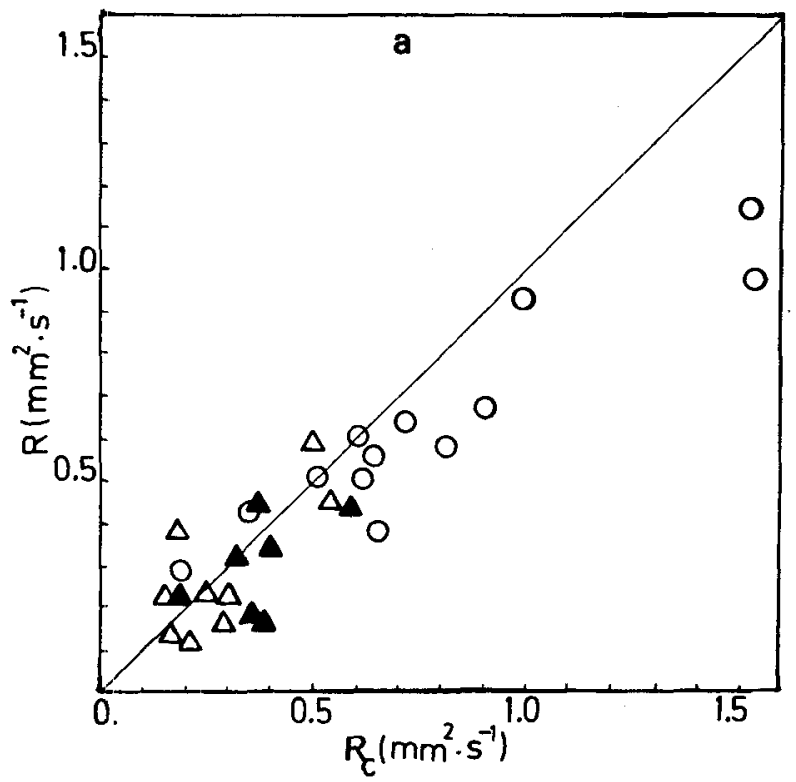

for each penetration in clouds with the concentration $C_{i}$ of large ice particles less than $5 \mathrm{~L}^{-1}$ (29 penetrations) and with $C_{i}$ greater than $5 \mathrm{~L}^{-1}$ (13 penetrations), respectively.

Most of the values plotted on Fig. 6a concern stratiform clouds and all of the values plotted on Fig. $6 \mathrm{~b}$ are relative to cumuliform clouds. On each diagram, the $45^{\circ}$ line represents the equality between the measured and the calculated value.

Fig. 6a shows that half of the measurements correspond to a dry growth regime (open triangles) and the other half to a wet growth regime (open circles) and the points corresponding to the growth regimes are not neatly separated, suggesting that the two characteristic profiles (horn shape and elliptical shape) have similar collection efficiencies, since the formulation given by Lozowski et al. (1979) does not take this difference into account. However, most of the points fall below the $45^{\circ}$ line, as the icing rate increases, that is to say when the liquid water content of the cloud increases. Consequently, the greater the liquid water content, the greater the difference between the measured and calculated value of the icing rate. The discrepancy may be due to the variations of the collection efficiency, but as suggested by Carras and Macklin (1973) and List (1977) a loss of water may occur by shedding under such conditions. Such shedding seems to increase proportionately to $E\left(W-W_{0}\right) V$ as suggested by wind tunnel experiments made at a speed of $30 \mathrm{~m} \mathrm{~s}^{-1}$ by the former authors.

In the two growth regimes the loss of accreted water may be due to the splashing of droplets. Latham and Mason (1961) have shown that splashing

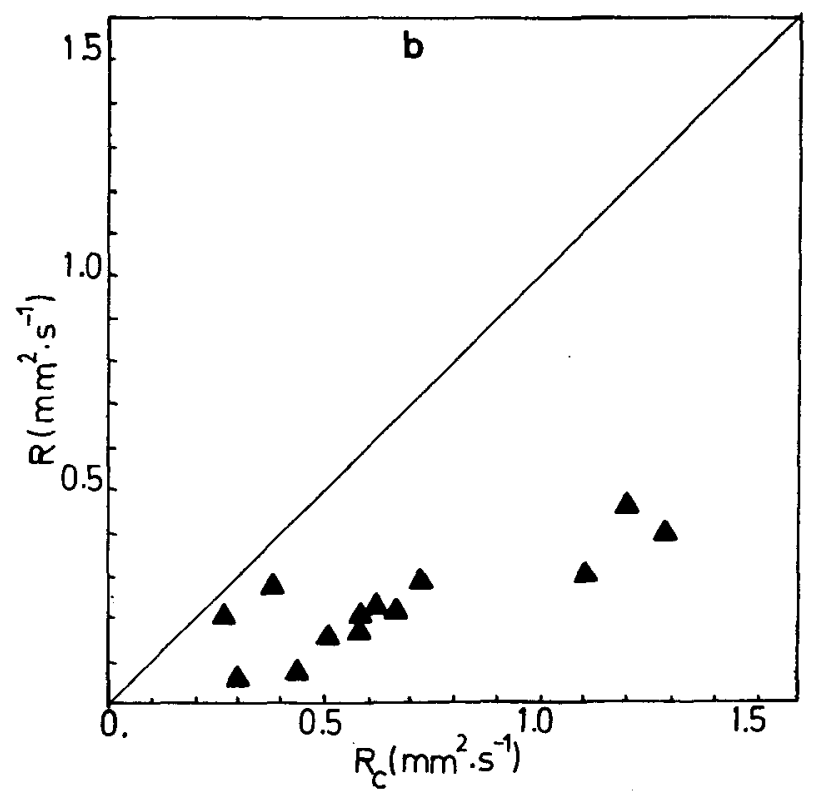

FIG. 6. The measured icing rate $R$ as a function of the calculated icing rate $R_{c}$ [from Eq. (5)], a) for concentration of large ice particles $<5 \mathrm{~L}^{-1}$ and $b$ ) for concentration of large ice particles $>5 \mathrm{~L}^{-1}$. 
may occur when the product of the diameter $d(\mu \mathrm{m})$ of the droplet and the velocity $V_{0}\left(\mathrm{~m} \mathrm{~s}^{-1}\right)$ of impact exceeds 1000 for their experimental conditions. For most of the present measurements, the product $V_{0} d$ exceeds this value which would imply that some water is lost by splashing. However, according to the results of Stallabrass (1978) about measurements of liquid water content made by monitoring the ice formed on rotating cylinders, this effect is in fact negligible in most of his experimental cases where the maximum value of the air speed was $125 \mathrm{~m} \mathrm{~s}^{-1}$ and the maximum median volume diameter of the droplet was $33 \mu \mathrm{m}$. (These latter conditions include the present experimental conditions where $V \approx 100$ $\mathrm{m} \mathrm{s}^{-1}$ and the maximum value of $d_{0} \approx 30 \mu \mathrm{m}$ ). Thus we will adopt this assumption.

\section{3) REDUCTION OF THE ICING RATE UNDER MIXED CONDITIONS}

Fig. $6 \mathrm{~b}$ shows a much greater difference between the measured and calculated values than in the former case. For measurements relative to penetrations in mixed clouds with a concentration of large ice particles greater than $5 \mathrm{~L}^{-1}$, the measured icing rate is about half the calculated value. We cannot explain this by simple shedding because all these measurements under mixed conditions were made under the dry growth regime. These observations lead to the suggestion that the reduced growth rate is due to the erosion of the ice deposit by the impinging of large ice particles.

In their wind tunnel experiment Lozowski et al. (1979) observed a smooth aerodynamic streamlining of the lateral surface of the accretion which suggested a possible erosion process wearing down the feathery rime that might otherwise grow outward in this region. The introduction of an ice crystal content (ICC) of $\sim 1.0 \mathrm{~g} \mathrm{~m}^{-3}$ reduced the overall mass growth rate by $\sim 25 \%$ for their experimental conditions $\left(V=122 \mathrm{~m} \mathrm{~s}^{-1}, T_{a}=-15^{\circ} \mathrm{C}, W\right.$ $\left.=0.4 \mathrm{~g} \mathrm{~m}^{-3}\right)$.

In Fig. 7 , the relative reduction in the icing rate $\left(R_{c}-R\right) / R_{c}$ is plotted versus the concentration of large ice particle $C_{i}$ for the measurements shown in Fig. 6b. The horizontal axis has two scales corresponding to the particle concentration $C_{i}\left(\mathrm{~L}^{-1}\right)$ and to the ice crystal content ICC $\left(\mathrm{g} \mathrm{m}^{-3}\right)$. For these measurements the temperature ranged from -8 to $-21^{\circ} \mathrm{C}$ and under these conditions, the main crystal habit is planar. The maximum dimension of the sampled ice particles varied from 500 to $1000 \mu \mathrm{m}$. By using the mass-dimension table given by Locatelli and Hobbs (1974), the corresponding mean mass of a crystal is $15 \mu \mathrm{g}$. This value allows us to get an idea of the ICC and to compare our measurements with the results of Lozowski et al. (1979). Most of the present flights made with $C_{i}>5$ particles $\mathrm{L}^{-1}$ show

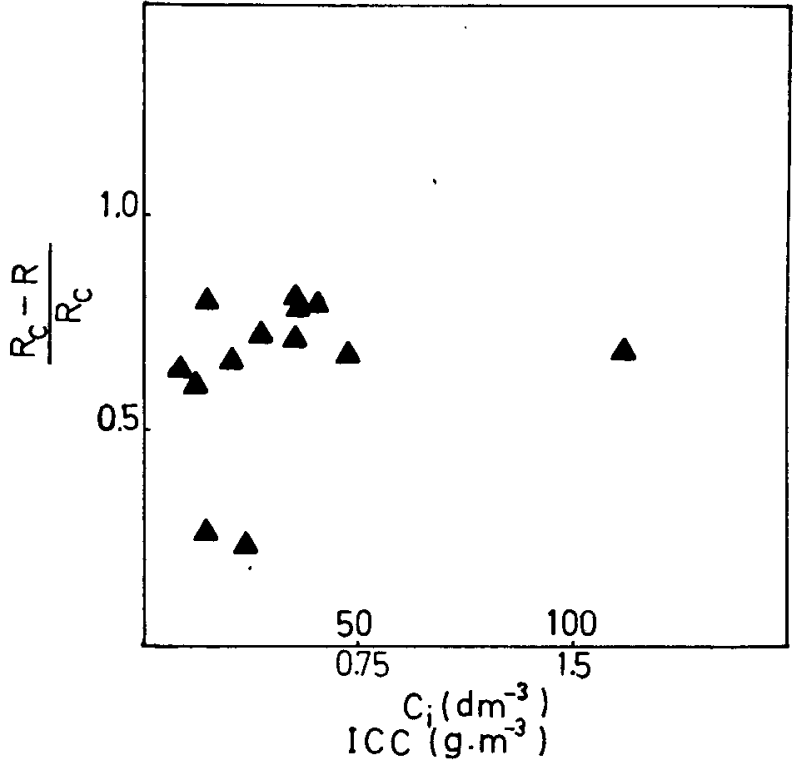

Fig. 7. Relative reduction in the icing rate versus the concentration of large ice particles and the ice crystal content of the cloud.

(Fig. 7) a reduction in the icing rate of $\sim 60 \%$. This figure suggests that the erosion observed from measurements in real clouds appears greater than the erosion observed from wind tunnel measurements made under similar microphysical conditions. This statement can only be made tentatively because the real effect of the ice particles on the ice growth is not well known and may be obscured by the fact that during the sampling time the concentration of large ice particles go through important fluctuations (see Fig. 1) and that the type of ice and the mass of each crystal may also vary. The precise relationship between the icing rate and the ice particles may well depend upon these parameters which have not been determined in the present study.

As explained in Section 2, in order to express the calculated icing rate, we have used the liquid water content estimated from the JW values rather than the total water content, which would take into account the water in the larger droplets $(d>30 \mu \mathrm{m})$ and in the ice particles. Taking into account this total water content would have increased even further the difference between the calculated icing rate and the measured icing rate for the penetrations shown in Fig. 6b, without much difference in Fig. 6a.

The use of the median volume diameter limited to the range $3-45 \mu \mathrm{m}$ in the calculation of the icing rate $R_{c}$, seems to be justified by the agreement between $R$ and $R_{c}$ in Fig. 6a. A greater value of $d_{0}$ corresponding to diameters between 3-200 $\mu \mathrm{m}$ would have increased $R_{c}$ and then induced a disagreement in Fig. 6a and an increase of the difference between $R$ and $R_{c}$ in Fig. 6 b. 


\section{Conclusions}

The present study is based on the energy balance at the riming surface of the cylinder and leads to an adequate prediction of the growth regirne of ice, despite the limitation of the probes used during the in situ experiments (relative error of $-20 \%$ on the measurements of the liquid water content).

The measured values of the icing rate are in reasonable agreement with the calculated values for the penetrations in supercooled clouds with few ice particles, taking into account the relative error of $\sim 20 \%$ in the measurements of the icing rate.

These measurements also suggest that the net effect of the mixed conditions (ice crystals present among supercooled droplets) is to reduce the icing rate by more than $50 \%$ possibly because of the erosion caused by the large ice particles impinging on the ice deposit. This effect is observed in cumuliform clouds at temperature ranging from -21 to $-8^{\circ} \mathrm{C}$ with most of the values near $-20^{\circ} \mathrm{C}$ and for ice particle concentrations greater than $5 \mathrm{~L}^{-1}$ (only particles with a diameter $>200 \mu \mathrm{m}$ are considered to be active ice particles for the erosion process).

According to the argument of Stallabrass (1978), the possibility of loss of water by splashing is considered as negligible under the present microphysical conditions (small cloud droplets with a diameter ranging from $\sim 10-30 \mu \mathrm{m})$. The loss of water by shedding is observed under a wet growth regime. The mixed conditions encountered were observed under a dry growth regime, and therefore no shedding may have occurred under these conditions.

The reduction in the icing rate under mixed conditions which we observed contradicts the conclusions of Lake and Bradley (1976) who attributed the high icing rates they observed to the high concentrations of the ice particles in a mixed cloud.

The mixed clouds studied in the present experiment existed for temperatures ranging from -8 to $-21^{\circ} \mathrm{C}$. Our conclusions cannot be generalized beyond these limits. It may be possible that, at higher temperatures, some ice particles with low density may stick to the surface when the temperature is such that a wet growth regime occurs.

Further experiments must be undertaken in order to study the effective role of the ice particles on the icing rate for a range of temperatures covering all the natural icing conditions and for various diameters of the icing probe.

It has been shown that the ice phase has to be taken into account for icing severity forecast, and that the direct effect of the possible erosion should be included in the modeling of icing, under the conditions described above.

Acknowledgments. The authors would like to express their appreciation to Professor R. G. Soulage for his guidance during the period of this study. We are indebted to Professor W. Hitschfeld for helpful suggestions and comments on the manuscript. We are grateful to Dr. Y. Pointin for stimulating discussions. We also wish to thank the DC $7 \mathrm{crew}$ for the acquisition of the data.

This research was supported by the "Direction des Recherches Etudes et Techniques" under the contract 79.34.183.

\section{APPENDIX}

\section{Nomenclature}

C cloud droplet concentration measured by the FSSP

$C_{i} \quad$ ice particle concentration

$C_{p} \quad$ specific heat of dry air at constant pressure $(1.005$ $\times 10^{3}$ )

$C_{w} \quad$ specific heat of water $(4.27$ $\times 10^{3}$ )

$D \quad$ cylinder diameter

$d_{0}$ median volume diameter of the droplet

$\epsilon \quad$ ratio of the molecular weight of water vapor and dry air (0.622)

$E \quad$ water droplet collection efficiency

$h \quad$ convective heat transfer coefficient $\left[=k_{a}\left(\rho_{a} V / D \mu_{a}\right)^{1 / 2}\right]$

ICC ice crystal content

$k_{a} \quad$ thermal conductivity of air $\left[=2.47 \times 10^{-2}+7.3\right.$ $\left.\times 10^{-4} T_{a}\right]$

$l \quad$ length of the cylinder

$l_{f} \quad$ latent heat of freezing $[=3.34$ $\left.\times 10^{5}+2.2 \times 10^{3} T_{a}\right]$

$l_{s}\left(T_{a}\right)$ vapor pressure over water at $T_{a}$

$l_{v} \quad$ latent heat of vaporization at $0^{\circ} \mathrm{C}\left(2.50 \times 10^{6}\right)$

viscosity of air $[=1.718$ $\left.\times 10^{-5}+5.1 \times 10^{-8} T_{a}\right]$

$P \quad$ free stream pressure

Pr Prandtl number (0.711)

$\rho \quad$ ice density

$\rho_{a} \quad$ air density

$\boldsymbol{R} \quad$ icing rate

$R_{c} \quad$ calculated icing rate

$r \quad$ recovery factor $(0.9)$

$r_{0} \quad$ median volume droplet radius

$R_{w} \quad$ rate of water mass caught per unit area $[=E V W 2 / \pi]$

Sc Schmidt number $(0.595)$

$\Delta S \quad$ cross sectional area of the ice deposit

$T_{a} \quad$ air temperature

$$
\begin{aligned}
& \mathrm{cm}^{-3} \\
& \mathrm{~L} \mathrm{~kg}^{-1} \mathrm{~K}^{-1} \\
& \mathrm{~J} \mathrm{~kg}^{-1} \mathrm{~K}^{-1} \\
& \mathrm{~mm} \\
& \mu \mathrm{m} \\
& \\
& \mathrm{W} \mathrm{m}^{-2} \mathrm{~K}^{-1} \\
& \mathrm{~g} \mathrm{m^{-3 }}
\end{aligned}
$$

$\mathrm{kg} \mathrm{m}^{-1} \mathrm{~s}^{-1}$

$\mathrm{m}$

$$
\mathrm{J} \mathrm{kg}^{-1}
$$

$\mathrm{Pa}$

$$
\mathrm{J} \mathrm{kg}^{-1}
$$

$\mathrm{kg} \mathrm{m}^{-1} \mathrm{~s}^{-1}$

$\mathrm{Pa}$

$\mathrm{kg} \mathrm{m}^{-3}$

$\mathrm{mm}^{2} \mathrm{~s}^{-1}$

$\mathrm{mm}^{2} \mathrm{~s}^{-1}$

$\mu \mathrm{m}$

$\mathrm{kg} \mathrm{m}^{-2} \mathrm{~s}^{-1}$

$\mathrm{mm}^{2}$

${ }^{\circ} \mathrm{C}$ 


$\begin{array}{lll}T_{s} & \text { surface temperature } & { }^{\circ} \mathrm{C} \\ V & \text { air speed } & \mathrm{m} \mathrm{s}^{-1} \\ V_{0} & \text { impact velocity of the droplet } & \mathrm{m} \mathrm{s}^{-1} \\ W & \text { liquid water content measured } & \\ & \text { by the JW } & \mathrm{g} \mathrm{m}^{-3} \\ W_{0} & \text { critical liquid water content } & \mathrm{g} \mathrm{m}^{-3}\end{array}$

\section{REFERENCES}

Ackley, S. F., and M. K. Templeton, 1979: Computer modeling of atmospheric ice accretion. CRREL, Rep. 79.4, 36 pp.

Carras, J. N., and W. C. Macklin, 1973: The shedding of accreted water during hailstone growth. Quart. J. Roy. Meteor. Soc., 99, 639-648.

Gayet, J. F., and M. Friedlander, 1979: The DC 7 research aircraft of the Centre d'Essais en Vol de Brétigny. Precipitation Enhancement Project, Rep. 13, WMO, 190-202.

Guillemet, B., and H. Isaka, 1979: The evaluation of dynamic and thermodynamic atmospheric parameters from the French DC 7/CEV aircraft. Precipitation Enhancement Project, Rep. 13, WMO, 203-208.

Heymsfield, A. J., and J. L. Parrish, 1979: Techniques employed in the processing of particle size spectra and state parameter data obtained with the T-28 aircraft platform. NCAR Tech. Note 137, $78 \mathrm{pp}$.

Lake, H. B., and J. Bradley, 1976: The problem of certifying helicopters for flight in icing conditions. Aeronaut. J., 419433.

Langmuir, 1. and K. B. Blodgett, 1946: A mathematical investigation of water drop trajectories. Army Air Force, Tech. Rep. $5418,348-393$.
Latham, J., and B. J. Mason, 1961: Generation of electric charge associated with the formation of soft hail in thunderstorms. Proc. Roy. Soc. London, A260, 537-549.

List, R., 1977: Ice accretions on structures. J. Glaciol., 19, 451465.

Locatelli, J. D., and P. V. Hobbs, 1974: Fall speeds and masses of solid precipitation particles. J. Geophys. Res., 79, 21852197.

Lozowski, E. P., J. R. Stallabrass and P. F. Hearty, 1979: The icing of an unheated non-rotating cylinder in liquid water droplet-ice crystal clouds. N.R.C.C. Rep. 96, 103 pp.

Ludlam, S. H., 1951: The heat economy of a rimed cylinder. Quart. J. Roy. Meteor. Soc., 77, 663-666.

Macklin, W. C., 1962: The density and structure of ice formed by accretion. Quart. J. Roy. Meteor. Soc., 88, 30-50.

Norment, H. G., 1976: Effects of airplane flowfields on hydrometeor concentration measurements. Preprints Int. Conf. Cloud Physics, Boulder, Amer. Meteor. Soc., 591-596.

Personne, P., J. L. Brenguier, J. P. Pinty and Y. Pointin, 1982: Comparative study and calibration of sensors for the measurement of liquid water content of clouds with small droplets. J. Appl. Meteor., 21, 73-80.

Ruskin, R. E., 1966: Measurements of water-ice budget changes at $-5^{\circ} \mathrm{C}$ in $\mathrm{AgI}$ seeded tropical cumulus. J. Appl. Meteor., 6, 72-81.

Stallabrass, J. R., 1978: An appraisal of the single rotating cylinder method of liquid water content measurement. N.R.C.C. Rep. 92, 29 pp.

- and P. F. Hearty, 1979: Further icing experiments on an unheated non-rotating cylinder. N.R.C.C. Rep. 105, 27 pp.

Vali, G., 1980: Cloud microphysics studies at the Spanish site for the Precipitation Enhancement Project. Proc. Third WMO Scientific Conference on Weather Modification, Clermont-Fd, France, 259-263. 